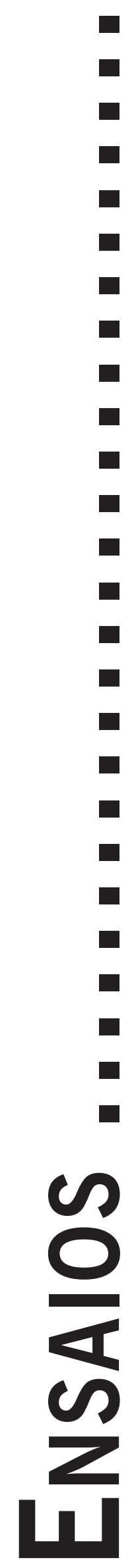




\title{
COMPLEMENTARIDADE INTUIÇÃO/EGO: AWARENESS NO PROCESSO DE RELAÇÃO CRIADORA DE INFORMAÇÃO
}

\author{
Complementarity Intuition/Ego: Awareness on the Process of Creative Relations of Information \\ Complementariedade Intuicíon/Ego: Sensibilización del Respecto de Información del \\ Respecto de la Información Creadora
}

† DÉcIo CASARIN

\begin{abstract}
Resumo: Considerando a frase: "Intuição é a inteligência do organismo", síntese da concepção de Perls sobre "organismo" e outras, que tecem sua teoria, este texto aborda a questão da morte, por conta do organismo, e a questão da vida, por conta da intuição, elegendo informação como produto do contato criado pelo saber da intuição. Propõe intuição e ego serem inseparáveis numa complementaridade que faz a fronteira entre organismo e ambiente. Examina a polivalência da awareness e postula o resgate do sentido na teoria do contato, por sua função indispensável na linguagem verbal.
\end{abstract}

Palavras-chave: Intuição; Organismo; Contato; Awareness; Sentido.

\begin{abstract}
Considering the phrase: "Intuition is the intelligence of the body", summary of Perls conception of "organism" and others, that support his theory, this article aboard the question of the death intended for organism, question of life intended for intuition, prizing information as contact's product created by intuition's wisdom. It proposes that intuition and ego must be the complementary and inseparable boundary between organism and environment. Assign a versatility to awareness, and requests to bring the notion of sense for contact's theory, by its necessary function in verbal language.
\end{abstract}

Keywords: Intuition; Organism; Contact; Awareness; Sense.

Resumen: Teniendo en cuenta la frase: "Intuición es la inteligencia del cuerpo", a corto Perls en el diseño del "cuerpo" y otros, que hacen de su teoría, este artículo aborda la cuestión de la muerte, por cuenta del cuerpo, y la cuestión de la vida, a cuenta de la intuición, la selección de la información como producto del contacto creado por el conocimiento de la intuición. Propone la intuición y el ego son inseparables de una complementariedad que es la frontera entre el organismo y el medio ambiente. Hace el examen de la versatilidad de la conciencia y plantea el rescate de sentido en la teoría de contacto, por su papel indispensable en el lenguaje verbal.

Palabras-clave: Intuición; Organismo; Contacto; Awareness; Sentido.

Fritz Perls conjugou as noções de auto-regulagem e "sabedoria do organismo", colocando neste toda a capacidade de regulagem interna e regulagem de relação com o ambiente. Nessa condição, é o saber do organismo que está ativo, no tempo-espaço real, durante a atividade de contato, guiando a relação da pessoa com o ambiente e a linguagem verbal, porque esta, enfim, prevalece no ambiente da realidade humana.

O conceito de organismo, se não for construção teórica sem base de realidade, deverá corresponder à informação acumulada durante toda a vida, desde os primórdios desta, codificada no DNA de toda célula. E, assim, essa informação terá de ser primariamente determinista, forçando obediência às leis necessárias e imutáveis de preservação da vida como um todo.
Por isso, um realismo teórico deve reconhecer a morte como fenômeno de resistência do organismo, necessária à preservação da vida que atravessa todos os "organismos particulares". Isso não requer dúvida. O organismo tem de estar forçando a morte do particular todo tempo, sem nenhum apego à vida deste, para exercer a finalidade primordial de, assim, forçar o aprimoramento da vida total com a constante criação de informação.

Caso o organismo privilegiasse vidas particulares, impossibilitaria a vida, mas, por outro lado, o organismo não pode viabilizar a luta entre vida e morte, de igual para igual, exclusivamente dentro de si próprio, sob pena de empacar no choque de forças contrárias, máximas, equivalentes. 
Fica, então, a hipótese de que o engenho do organismo criou um órgão vivo, no cérebro do particular, dotado de saber criador de informação, para ter exclusividade em se opor ao próprio organismo, numa complementaridade em que os contrários convergem para a mesma finalidade de constante recriação da vida. O único recurso possível a essa recriação terá de ser informação, porque a resistência não sustenta vida sem aquela. Isso parece óbvio.

Assim, o organismo foi forçado a apreender com as adversidades do ambiente e - no estágio evolutivo que já exigia capacidade de contato do particular com esse ambiente - gerou informação materializada num cérebro intuitivo, justamente, para este criar informação de contato, inicialmente ainda sem linguagem verbal.

Considerando-se que o organismo continuou apreendendo e desenvolvendo esse órgão ao longo da vida, então, no estágio humano, fez esse cérebro dobrar-se noutra estrutura orgânica e funcional, já estruturada em linguagem verbal, constituindo o ego. A complementaridade organismo/intuição acabou por gerar outra complementaridade - intuição/ego - atravessadas pelo corpo do ser particular, junto ao ambiente, integradas na ação do contato.

Nessa complementaridade, o componente da intuição é fonte do saber veiculado pelo pensamento natural da awareness com formação de gestalten, no sentido de criar informação perante qualquer eventualidade junto ao ambiente, com gozo ou sofrimento em contato.

Isso podemos depreender do fato de animais desenvolvidos, a exemplo de gatos e cachorros, por um lado, serem capazes de criar engenhos para suas intenções junto ao ambiente, realizar tarefas inteligentes, complexas, que exigem um cérebro capaz de fazer associações de sentido sem o recurso da abstração verbal; e, por outro lado, já começarem a associar sons e gestos numa comunicação com sentido e contato com seus amigos humanos. Nossos antepassados inventaram a linguagem verbal graças à potência do saber da intuição, com a provisão do ambiente externo, na experiência, que incitou o organismo a criar esse órgão da fala.

Awareness, em sua amplitude na atividade de contato, deve ser examinada, deixando de fora a awareness interna, celular ou conduzida pelas vias do sistema nervoso nos processos de comunicação da intuição com o organismo. A imensa distância funcional de complexidade entre awareness de contato e a outra, novamente nos obriga a privilegiar a intuição como o saber que emerge da curiosidade causada pelo ambiente, comunicando-se - esse saber da intuição - com o organismo pela via interna, sem perda de sua autonomia, cuja capacidade também se comunica com a linguagem verbal, o que o organismo não pode fazer.

Este não tem awareness de contato, é potencial da informação que dele será extraída e ativada pela intuição, justamente, para a finalidade do contato. No contato, a intuição pensa com a inteligência do senso de sentido, que no estágio humano servirá de base para o pen- samento verbal ter sentido real junto à experiência. Sem essa base, não há como a pessoa distinguir um conteúdo verbal desconexo de um conteúdo com sentido, junto à vivência do verbo no substantivo da palavra. A atividade inteligente e plenamente capaz de exercer essa excelência informacional é awareness de contato, propriedade exclusiva do componente da intuição, na complementaridade intuição/ego.

A capacidade de discernir uma sensação (p.ex., audição de som externo), já acontece em animais, e, portanto, não é propriedade do ego, tal como a capacidade de associá-la com um sentido para guiar a intencionalidade de conduta junto ao ambiente. É propriedade da intuição, ativando awareness nos sentidos corporais. Observe-se que - de longe - essa não se trata da mesma awareness capaz de penetrar numa articulação de palavras e vasculhar seu vínculo de sentido com a experiência. Esta última já é awareness fundida em suprema inteligência, somente atingida pelo ser humano versado em linguagem.

Assim, a awareness das sensações, digamos, awareness sensorial, é a mais primitiva no contato, podendo acontecer em mera reação reflexa, sem criação de informação. A outra cria imediata informação ao acontecer contato. Todas essas variações e graus de awareness são simultâneas, fazendo parte de um fenômeno polivalente e evolutivo, que denominamos awareness.

Informação tem um componente de novidade e antecipação de possibilidade, diminuição da incerteza que permeia nossa realidade todo tempo. Durante o contato, cria alguma capacidade que não existia, por mínima que seja. No momento da criação, informação é ato exclusivamente subjetivo, ainda sem forma ou materialidade de memória; é princípio de possibilidade capturado nas relações de sentido que estão atravessando a experiência. Nesse momento, é o saber da intuição que dá origem à informação, mas esta logo se transmuta numa representação que terá materialidade para ser estocada como memória ou transmitida para fora da subjetividade, quando, então, é o ego que opera essa finalização. Se a intuição é o único poder que dá origem à informação no contato, esta, para ser consumada e aplicada, depende do ego. Assim, a intuição funciona como o sujeito do saber e o ego como agente do fazer ou materializar a informação e sua utilização na vida. Ambos numa complementaridade inseparável.

A teoria do contato da Gestalt-terapia omite o fenômeno real do sentido, reconhecido por semiologistas. Com isso, deixa um lapso para compreender o fator essencial de função da awareness no processo de relação criadora de informação com o ambiente, porque sem vínculo de sentido, a sucessiva formação de gestalten não seguiria um movimento de inteligibilidade criador dessa informação, tanto no mundo animal como humano.

O sentido é real, acontece entre todas as expressões da vida, como um movimento de vínculo de umas com outras, pela própria constituição da Matéria que nos ori- 
ginou, desde antes da vida biológica. É um fenômeno de relação da mudança com a resistência, permitindo uma ordem e coesão, no movimento incessante dessa matéria em qualquer instância.

Para nossa psique, assentada na dualidade intuiçãol ego, inseparáveis da matéria de um corpo, o sentido proporciona um senso de inteligibilidade na experiência subjetiva de contato com a exterioridade do ambiente e interioridade do corpo ou sua película intermediária entre dentro e fora.

O fenômeno de contato, descartados todos seus aspectos periféricos, é um fenômeno criador de informação para o ser particular, presente com seu corpo e ação junto ao ambiente. Depende da recepção dos sentidos corporais, ainda num estágio de awareness sensorial; passa pela representação das idéias invariavelmente conectadas à memória; sustenta-se em saber que permeia a experiência com senso de sentido, graças à awareness ou inteligência da intuição.

Nesta hipótese aqui finalizada, então, é inconcebível qualquer outra possibilidade que não seja de a intuição e ego serem uma complementaridade inseparável, a qual sim, é que será a fronteira de relação entre o organismo e o ambiente, assentados no corpo. Com exceção do ambiente, que é externo, nenhum desses componentes terá poder independente sobre qualquer outro, sendo o contato a resultante da integração de todos.

† Décio Casarin - Formado em Medicina (1963), tendo obtido seu título de especialista em psiquiatria em 1973. Desistiu da psiquiatria em 1975, passando ao campo da psicoterapia. Estuda Gestalt-terapia durante três anos entre 1975 e 1977, em grupo dirigido por Adriana Schnake (Nana) e Francisco Huneeus (Pancho), terapeutas chilenos. Desde 1977 trabalhou em Gestalt-terapia como terapeuta individual, maratonas e grupos. Nos últimos anos, recolheu-se para aprofundar estudo de Semiótica e escrever o livro Contato (Ed. Revinter), lançado no último Congresso Nacional de Gestalt-terapia, no Rio de Janeiro. Deixou-nos prematuramente, em maio desse ano.

Recebido em 20.01.07

Aceito em 18.08.07 